\title{
Research on Evaluation of Enterprise Performance Based on BP Neural Network Improved by Levenberg-Marquardt Algorithm
}

\author{
Wanyin Du \\ Department of Information Management, The Central Institute For Correctional Police, Baoding, \\ 071000, China
}

Keywords: Artificial neural network; BP network; Levenberg-Marquardt algorithm; Performance

\begin{abstract}
BP neural network is a multilayer feedforward network for training according to the error back-propagation algorithm, its main advantage is the strong non-linear mapping ability, but the training of BP neural network is easy to fall into local minima, and slow convergence speed. In this paper, through the Levenberg-Marquardt algorithm to improve the BP neural network , using LM algorithm terative results dynamically adjust the convergence direction of neural network,so that each iteration error are decreased, and the convergence speed is fast.Through example analysis, show that the improved BP neural network utility and effectiveness in enterprise performance level evaluation.
\end{abstract}

\section{Introduction}

Artificial neural network from the origin to the present, no substantive progress on the connection weights of the problems in the research on the process . Then BP neural network is put forward, and provides a method to solve this problem.In the present stage in the field of artificial neural network, the application of BP neural network is still the most extensive. But it also has some shortcomings, the training time is long, easy to fall into local minimum.

Using the method of genetic algorithm and BP neural network combination, by modifying the initial values and parameters know which genetic algorithm to a certain degree of improvement stability and high efficiency of the neural network, can be optimized for the original algorithm.

\section{Neural network}

In the ANN model, a multilayer feed-forward neural network model is the most widely used model. BP(Back Propagation) neural network is one of the most common multilayer feed-forward neural network model, this paper uses genetic algorithm to study the optimization of neural network.

BP (Back Propagation) network is a group of scientists led by Rumelhart and McCelland put forward in 1986 , is a kind of error back-propagation algorithm for training multilayer feed-forward network, its learning rule is to use the method of steepest descent, to constantly adjust the network weight value and threshold value by back propagation, make the network and the minimum sum of square error. BP neural network is mainly composed of an input layer, one or more hidden layers and one output layer, the mutual connection between the layers of neurons, but between each layer between the neurons are not connected relationship.

The learning process of the BP neural network model composed of by two parts,forward and backward .In the forward process of communication, information from the input layer through the middle hidden layer to the output layer weighted propagation, in the output layer to obtain the input of the network response, output value by comparing the function calculation and target output value, if there are errors, error back propagation along the route before the return, i.e., from the output layer after each intermediate the hidden layer to adjust the connection weights, finally back to the output layer, to reduce the error, with the neural network error reverse spread to revise the weights continuously, the entire network accuracy of input information in response to natural also improved. 


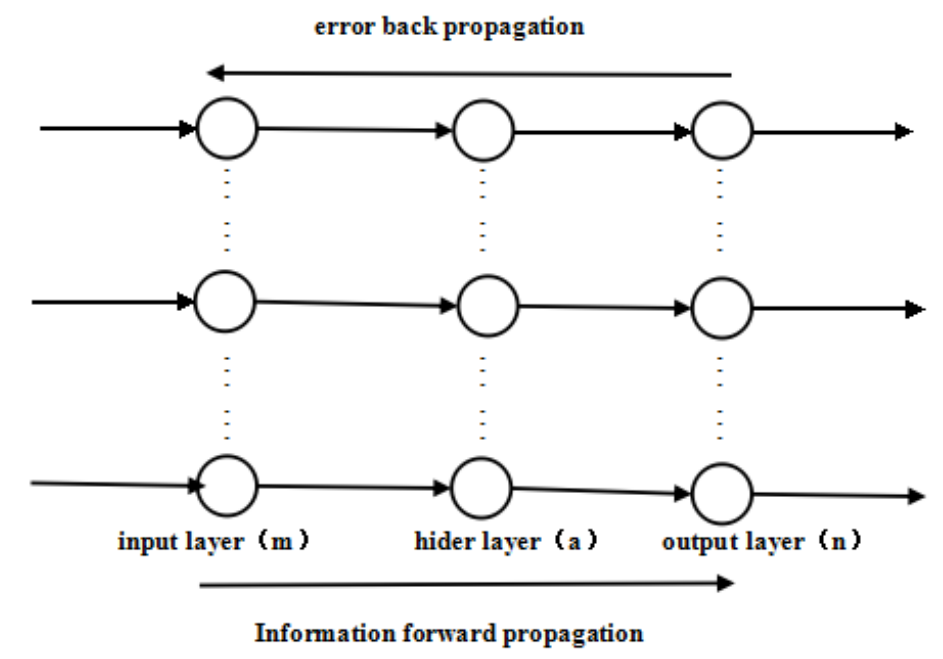

Figure 1.A classical 3-layer BP network model

\section{Improvement of the traditional BP algorithm}

In traditional BP algorithm, the initial connection weights and thresholds are set randomly.As a result, selecting the wrong initial value will directly affect the network's convergence and the final steady state, and the network learning is easy to fall into local minimum.In addition, in the process of BP neural network learning, it mainly updates the connection weights and threshold of the network, while in the traditional BP network, it finds the right value through continuous training. However, excessive training or lack of training are not leading to ideal result, and will result in phenomenas like "over-fitting", thus affecting the generalization ability of the network.

BP neural network show the artificial and the slow convergence speed and the influence of initial weights on the results of random defects to determine the structure, and the BP neural network has the learning process is easy to fall into local minimum, prone to shocks and network redundancy connection or node and other defects, determining the hidden layer node number is still not unified method.Therefore, many scholars have made improvements or make it with other algorithm of BP neural network are combined to overcome these shortcomings. The improved method can be classified into two categories: the first category is improved based on the standard gradient descent method, such as additional momentum method, resilient BP algorithm, adaptive adjustment of parameters method; the second category is the improved method based on standard numerical optimization, such as Newton algorithm, conjugate gradient method and Levenberg-Marquardt (LM) algorithm. This paper uses the Levenberg-Marquardt algorithm to improve the BP algorithm.

The essence of training on BP neural network is a nonlinear optimization problem of the objective function, different BP algorithm based on gradientinformation, a derivative of LM not only use numerical optimization algorithmbased on objective function, but also the use of two order derivative informationof objective function. The LM algorithm for iterative formula:

$$
W_{\mathrm{k}+1}=W_{\mathrm{k}}-\left(J^{T} J+\mathrm{u} I\right) J^{T} \mathrm{e}
$$

Among them, e is the error vector; $\mathrm{J}$ is Jacobian matrix network error on theweight of derivative; I as a unit matrix; $\mathrm{u}$ is a scalar value,its value determines the algorithm based on Newton's method or the gradientmethod to achieve.LM algorithm based on the iteration results dynamically adjust the iterative convergence direction, make the iterative error every time error is decreased, fast convergence speed.

\section{Enterprise performance evaluation index system}

The comprehensive evaluation of enterprise performance is one of the core of enterprise management, its final purpose is through the performance analysis of a full range of understanding the business situation, for make a system and reasonable evaluation to enterprise management 
effectiveness .A very practical problem of performance evaluation in enterprises often encounter is very difficult to determine the performance indicators of objective and quantitative. Under the current system, in the reflection of the invisible influence enterprise future development aspect, the current accounting income is a short-sighted index".If the emphasis on profit one sidedly, easy to cause the operators' short-term behavior in pursuit of short-term benefits and long-term benefits expense of enterprise, make enterprise managers not to may reduce the current profit target capital investment for the pursuit of long-term strategic objectives and contribute to enterprise, short-term speculation.Performance evaluation based on financial indicators of the traditional can not adapt to the comprehensive performance evaluation of enterprises now, there are many limitations and drawbacks.In the existing performance analysis tools (such as: SWOT analysis, PDCA, SMART, 80/20 cyclic rule principle on the basis of law), we put forward a method of BP neural network evaluation the enterprise performance based on LM algorithm .

To evaluate the performance of a specific enterprise, first of all to establish thesystem of evaluation index system, and then to use appropriate methods of evaluation.According to the the principle comprehensive and comparability of evaluation , mainly from the enterprise financial, customer perspective, innovation development ability and the internal development this 4 aspects to comprehensive evaluate enterprise performance, the evaluation index system is shown in table 1.

Table 1 the enterprise performance evaluation index system

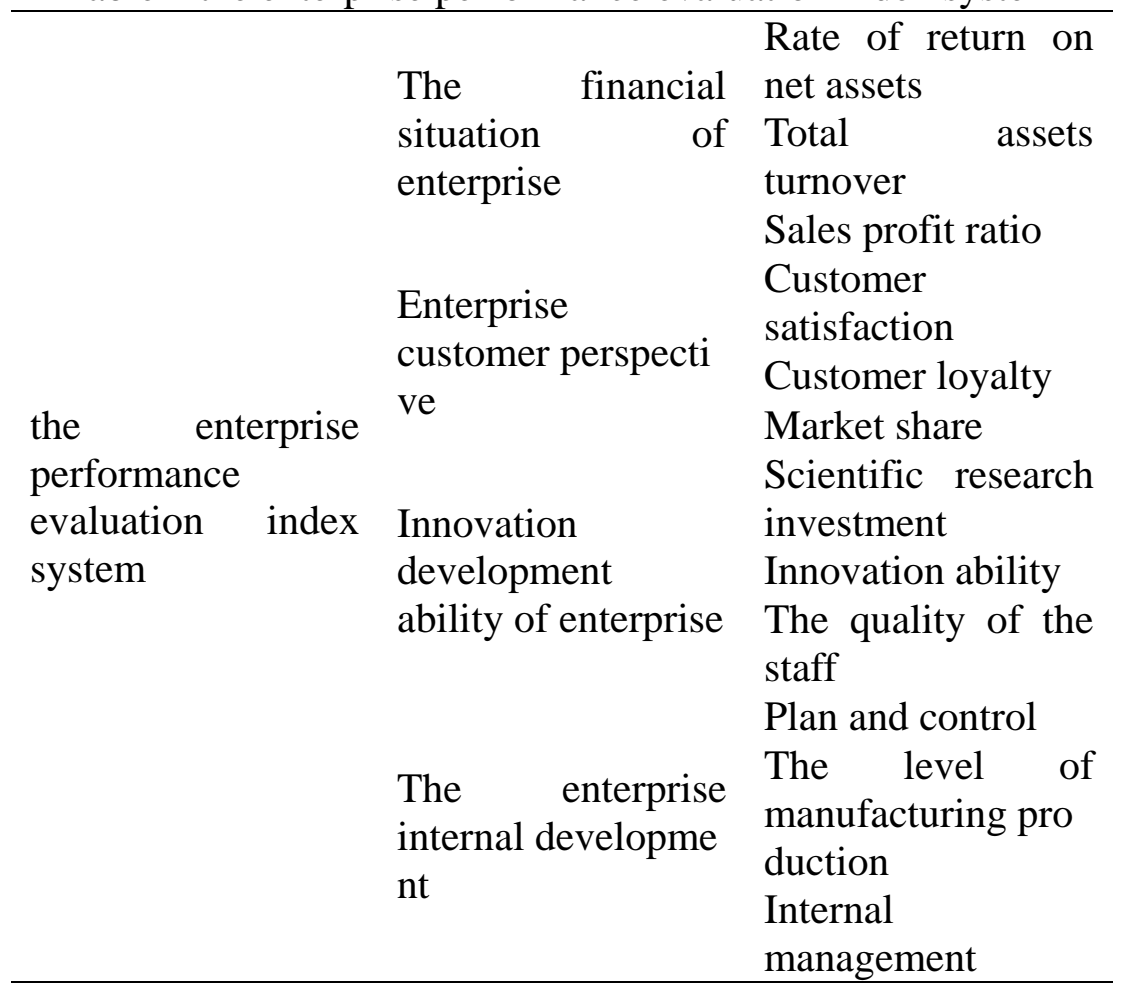

\section{Application of improved BP network in enterprise performance evaluation}

(1) obtaining the sample data and design evaluation grades

Object analysis selected 25 enterprises in Anhui Province as the empirical,enterprise performance evaluation index data obtained by various means, as a training unit neural network.Among them, the network marketing evaluation index data of 20 enterprises as the training samples for neural network learning, and the corresponding performance evaluation of enterprise value as the desired output of the network.The corresponding value of enterprise performance evaluation can be obtained by using the fuzzy comprehensive evaluation method. The specific application examples on the fuzzy comprehensive evaluation method, can reference.

Enterprise performance index, denoted as SI[0,1], reviews set (poor,general, qualified, good,excellent), the corresponding scale as shown in table 2. 
Table 2 the performance of enterprises scale

\begin{tabular}{llllll}
\hline $\begin{array}{l}\text { Perfor } \\
\text { mance }\end{array}$ & $0 \leq S \prec 0.3$ & $0.3 \leq S \prec 0.5$ & $0.5 \leq S \prec 0.7$ & $0.7 \leq S \prec 0.9$ & $0.9 \leq S \leq 1$ \\
Index & & & & \\
\hline $\begin{array}{l}\text { Perfor } \\
\text { mance } \\
\text { levels }\end{array}$ & & & & \\
\hline
\end{tabular}

(3)simulation and training network

To obtain the network training sample data can be trained on a network, The numbers for evaluation index of 1-20 data of enterprise as the training unit input of BP neural network training, the learning accuracy given as $E=0.0001$,comprehensive evaluation of each sample firm performance as expected output value network.The network is trained by using the software of Matlab, when the training error reaches the precision requirement, training stop. The code for the 20-25 business data to test the network evaluation and prediction accuracy as the simulation samples,the simulation results are shown in table 3.

Table 3 the model simulation results

\begin{tabular}{|l|l|l|l|l|l|}
\hline Enterprise code & 21 & 22 & 23 & 24 & 25 \\
\hline $\begin{array}{l}\text { The model simulation } \\
\text { results }\end{array}$ & 0.6545 & 0.5436 & 0.8521 & $\begin{array}{l}0.75 \\
26\end{array}$ & $\begin{array}{l}0.352 \\
1\end{array}$ \\
\hline $\begin{array}{l}\text { Evaluation result of } \\
\text { samples }\end{array}$ & 0.6758 & 0.5214 & 0.8479 & $\begin{array}{l}0.74 \\
95\end{array}$ & $\begin{array}{l}0.335 \\
9\end{array}$ \\
\hline The relative error (\%) & 3.21 & 2.22 & 0.49 & 0.41 & 4.82 \\
\hline $\begin{array}{l}\text { The grade of simulation } \\
\text { evaluation results }\end{array}$ & $\begin{array}{l}\text { qualifi } \\
\text { ed }\end{array}$ & $\begin{array}{l}\text { qualifi } \\
\text { ed }\end{array}$ & good & good & $\begin{array}{l}\text { gener } \\
\text { al }\end{array}$ \\
\hline $\begin{array}{l}\text { The grade of } \\
\text { evaluation results }\end{array}$ & $\begin{array}{l}\text { qualifi } \\
\text { ed }\end{array}$ & $\begin{array}{l}\text { qualifi } \\
\text { ed }\end{array}$ & good & good & $\begin{array}{l}\text { gener } \\
\text { al }\end{array}$ \\
\hline
\end{tabular}

Through the BP neural network evaluation model simulation results ,the author found that, in good agreement with the model simulation results and sample evaluation results, show that the network has good generalization ability, it is completely feasible to use the model to evaluate the enterprise performance levels.

\section{Conclusion}

In this paper aiming at some shortcomings improved BP neural network ,Levenberg-Marquardt algorithm is adopted to optimize the BP neural network, which can optimize the network from the aspects of the convergence direction, convergence speed, greatly improves the operation speed and reduce the error of the original network. The last example analyzed through the MATLAB simulation platform, optimized model calculation result is very perfect, it showed that the BP neural network improved model has a strong applicability in the evaluation of enterprise performance.

\section{References}

[1] HE Jian-guo,JIANG Guo-yin,TIAN Bo. Credit evaluation system research based on improved BP neural network[J]. Computer Engineering and Design,2006, 2(4):605-607.

[2] CHAI Yi,YIN Hong-peng,LI Da-jie. BP neural network adaptive optimization design based on the improved genetic algorithm[J]. Chongqing university journal, 2007,30(4):91-96.

[3] ZHANG Hongxia,SHEN Yuzhi,HANG Zhaoliang.Local government performance evaluation model based on fuzzy comprehensive

[4] Lei Huang,Shu-bi Zhang,Qiu-zhao Zhang .Application of particle swam optimization BP neural network to GPS elevation fitting[J].Journal of Geomatics,34 (6) ,2009,18-19. 
[5] Jia-yang Wang ,Chun Guo,Zuo-yong Li .Preliminary evaluation model of mine safety based on neural networks optimized by particle swarm optimization[J].Journal of Computer Applications,30 (s1),2012,74-75.

[6] Quan LONG,Yong-qian Liu,Yong-pingYang.Fault diagnosis method of wind turbine gearbox based on BP neural network trained by particle swarm optimization[J].Acta Energiae Solaris Sinica,33(1),2012,121-123

[7] CAI Sijing; CHEN Haiyan; ZHENG Minggui.Evaluation of capacity of sustainable development of energy in Beijing based on GA-BP model[J].Journal of Liaoning Technical University(Natural Science),2009, 28(1): 5-9 